\title{
The 30,000-year ceramics comeback
}

Despite the ubiquity of metals in machinery, ceramic tools and systems can perform better under the most extreme conditions. $M^{2}$ Laboratory are a group of scientists at Tianjin University in China with an Amongst the ranks is Bians. amofessor, doctoral supervisor and deputy director of the key laboratory of Advanced Ceramics and Processing Technology. Ceramics are a broad class and $M^{2}$ lab's research examines almost every dimension of these multifaceted materials, leading to finding new of novel ceram the manufacture of ceramics, and developing methods to evaluate and quality-control ceramic products.

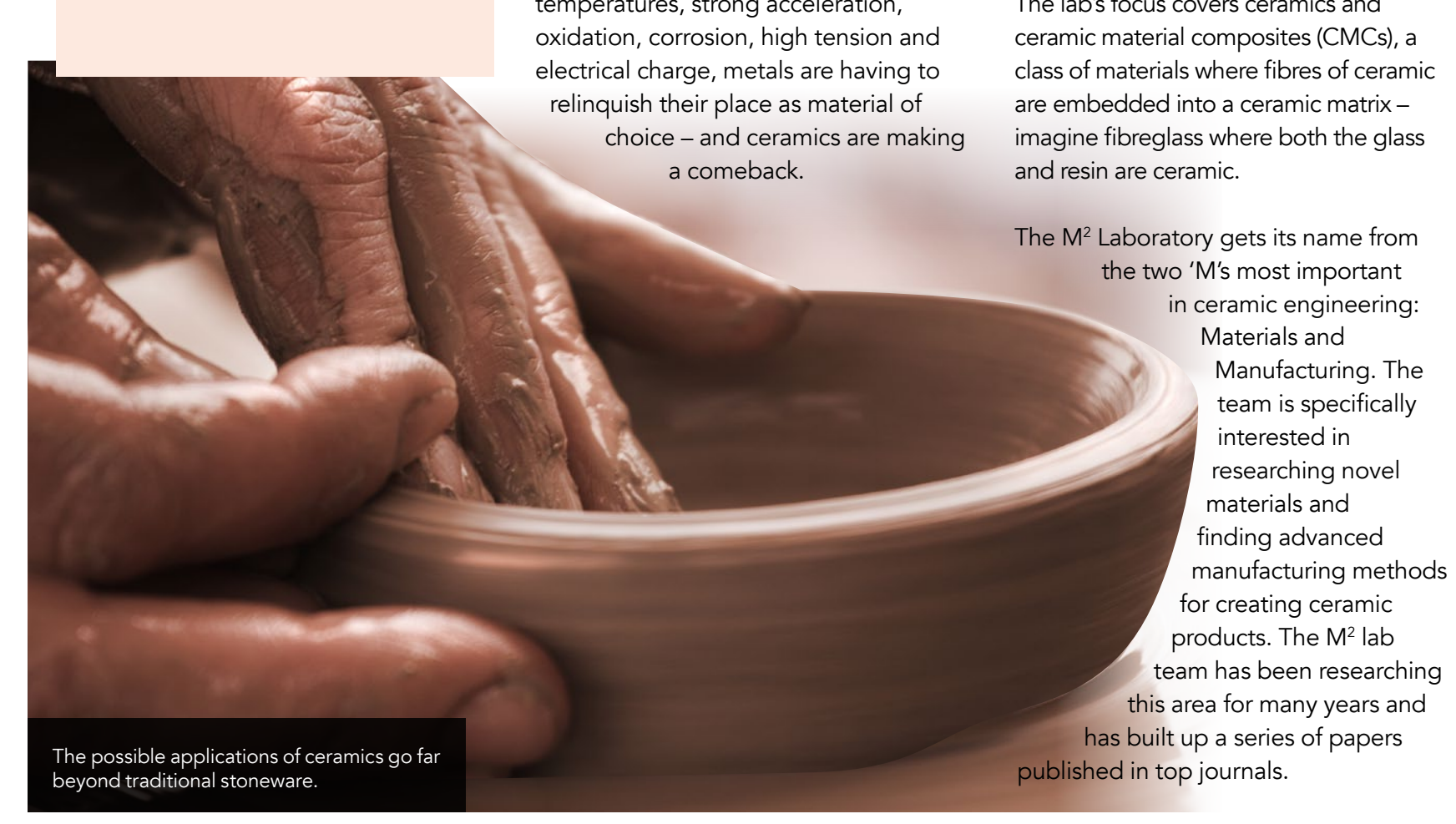

he oldest piece of ceramic made
by humans is probably over thirty
Ceramics are a broad class of materials. thousand years old. It is a small statue of a woman from a prehistoric settlement in the Czech Republic. Twenty thousand years later, clay-base ceramics formed some of our most important tools - containers for water and food, art objects, tiles and bricks, dug into the ground.

As the millennia passed and metals to make an exit. Metals' strength and malleability have been valuable for developing many kinds of tools, even today; but as those tools are put under ever-increasing challenges in constantly harsher environments, it is becoming cl that metals are not up to some of the toughest scientific applications.

In environments with high or low temperatures, strong acceleration, oxidation, corrosion, high tension and . They are always solids, but can be formed into any shape, and can have a broad range of compositions. Earthenware, glass, porcelain and brick are commo examples. Generally, ceramics are hard, have high melting points, low are inalastic. However, the properties of are instic. However the propertios of exceptions to these rules.

New research into ceramics has resulted in applications for aerospace, military and even household items. Ceramic ball bearings, for example, will last three times as long as their steel counterparts.

THE M² LABORATORY The M² lab from Tianjin University of China are a laboratory with a very varied . lab's focus covers ceramics and . became more prevalent, ceramics began interest in ceramics, matching the wide

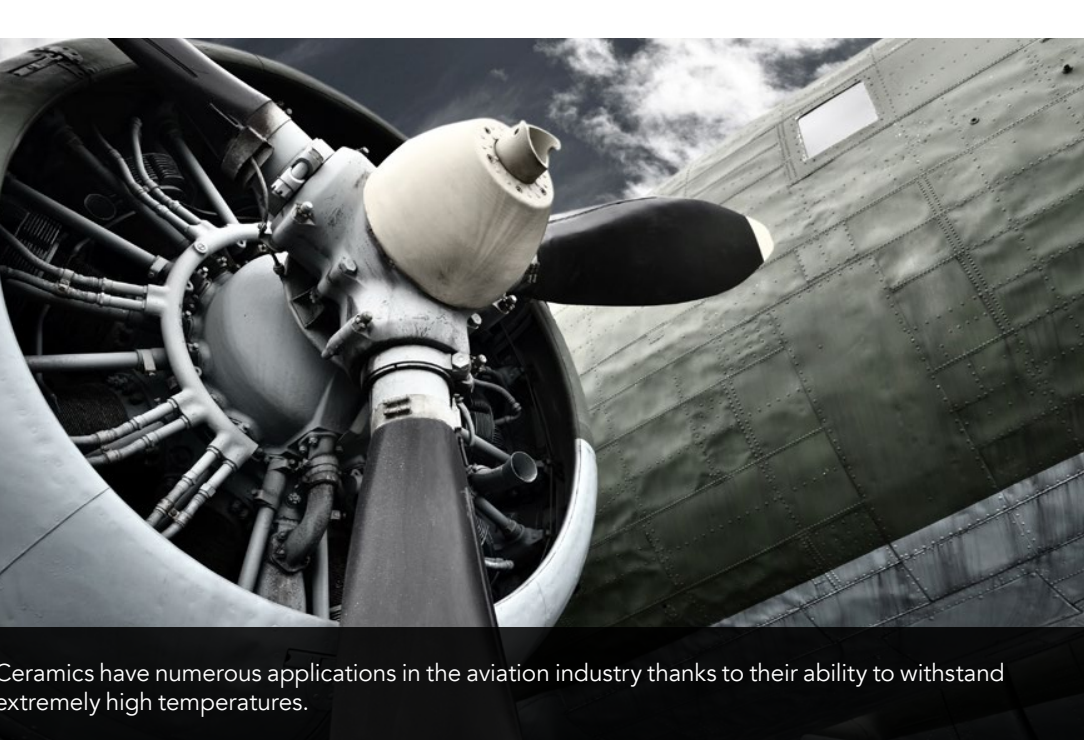

TRIBOLOGICAL MATERIAL SYSTEMS Tribology - the excitingly named study f surfaces which rub together - is a field hine Tribologists are mettisciper scientists who spend a lo of their time thinking about friction, lubrication and wear. Traditionally, metals have been used for tribological applications, but require lubricating oils. Not only are these oilbased lubricants problematic to dispose of, they also consume a vast amount of non-renewable resources. Compounding these issues, oil-based lubricants are associated with a high temperature rise, which can cause metals to expand and fall especially high-speed machinery.

The $\mathrm{M}^{2} \mathrm{l}$ ab is part of a research movement to replace metals in many applications advantamis ceramics have further dvantages over metals because of their and high wear resistance. Possibly the most significant advantage of ceramics over metals is that they are generally farly chemically inert As a result, lubricating oils could be replaced with a more environmentally friendly, low viscosity and non-polluting alternative: water

A number of experiments have been performed by many researchers to find the ideal combinations of ceramic materials, identifying $\mathrm{Si}_{3} \mathrm{~N}_{4}$ and $\mathrm{SiC}$ as promising candidates. Despite the numerous advantages of using ceramics and water in tribological systems, educing the friction is a major priority. $\mathrm{M}^{2}$ lab tested a water-based lubricant with several additives, in a system which paired a $\mathrm{Si}_{3} \mathrm{~N}_{4}$ surface with a $\mathrm{SiC}$ surface. All of the additives tested were advantage of water over oil as a lubrican was retained. Compared to ISO VG 2, the most commonly used lubricant oil, the water-based lubricant was found to be almost equal in its ability to reduce friction, while reducing the heat generated by $40 \%$.

Based on these material systems, the $\mathrm{M}^{2}$ team has more recently created a syste lubricated using only sea water, designed to be used in boat propellers.

\section{LUBRICANT-FREE}

CERAMIC SYSTEMS

Even better than a water-based

The $\mathbf{M}^{2}$ laboratory gets its name from the two 'M's most important in ceramic engineering: Materials and Manufacturing.

never have been possible with metal tribological systems, but ceramics are different. Ceramics can withstand much higher temperatures, and some can even self-lubricate. Two self-lubricating ceramics of particular interest to $\mathrm{M}^{2}$ are $\mathrm{ZrO}_{2}$, and $\mathrm{C}_{5} \mathrm{SiC}$, which has carbon fibres reinforcing a SiC matrix.

It was once thought that smoother surfaces always led to a reduction in friction and wear, but more recent products, using techniques like surface grinding and polishing. These processes are more complex for ceramics than metal because of their brittleness, The $\mathrm{M}^{2}$ lab is pioneering new theoretica and experimental work to make processing methods more reliable and efficient. The lab has also developed mathematical tools which allow ceramics experts to accurately estimate the heat and grinding forces which will occur

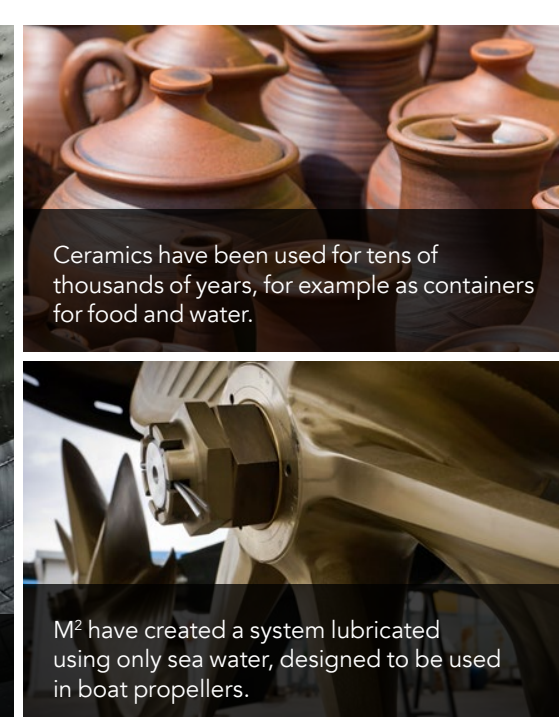

of specific microstructures which can reduce friction and wear further of lubricated materials. The team at $\mathrm{M}^{2}$ were interested in discovering the best microstructure of the surfaces of $\mathrm{ZrO}_{2}$ and $\mathrm{C}_{5} \mathrm{SiC}$ when they are paired in an unlubricated tribological system. $\mathrm{M}^{2}$ found that the best tribological properties are when the fibres in one material are perpendicular to the fibres in the other. These materials perform particularly well under high use in the aviation or nuclear industries.

GRINDING CERAMICS INTO SHAPE An under-developed aspect of ceramic An ability to shape them into the desired 

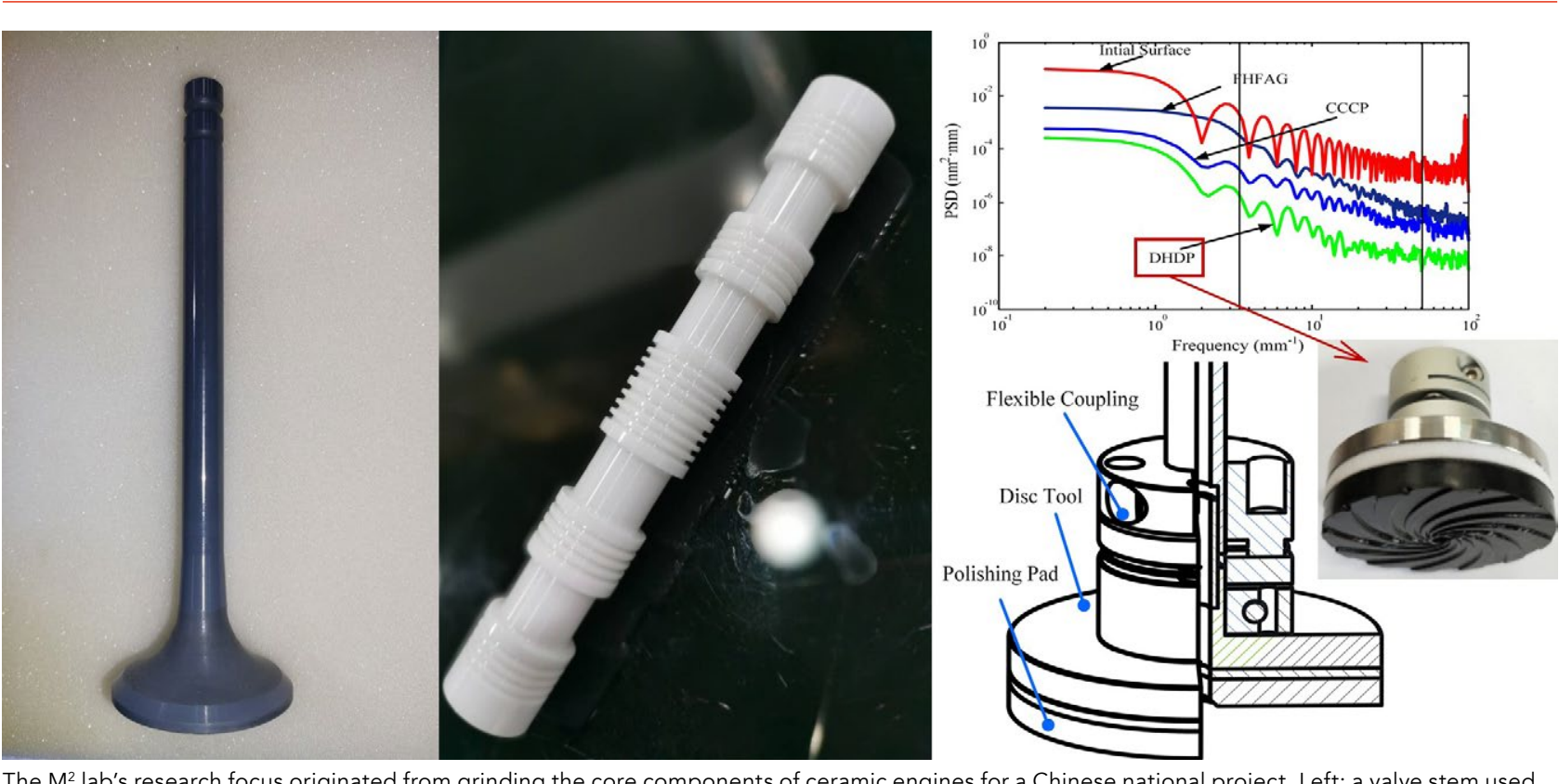

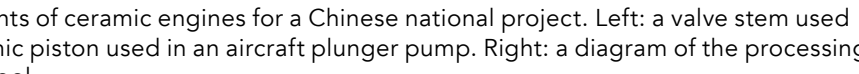
in cechnology for creating an optical surface with sub-aperture polishing tool.
tech

like diamond scratching, flat-grinding and cup-wheel grinding

The team has also developed a method to monitor damage to materials caused by the grinding process, using a tool As a ceramic composite is ground, many types of damage can occur to the fibres and the matrix. By matching frequencies emitted by materials as they were ground to damage identified using scanning electron microscopy, $\mathrm{M}^{2}$ built a tool which
can identify damage as it occurs. Ceramics manufacturers using this tool would have of the quality of their products.

\section{POLISHING TECHNOLOGY}

Polishing is used to smooth the surface of a ceramic material, but like grinding, it is difficult for ceramics because of their hardness. To counter this problem, the called fluid hydroded a new technology grinding (FHFAG).

Commonly used optical polishing methods use a grinding pad pressing directly onto the material. The novel method proposed by $\mathrm{M}^{2}$ introduces an abrasive liquid film between the pad and the surface. This allows quick removal of
material while having several advantages: most importantly that by changing the thickness of the liquid layer, coarse and the same grinding pad, reducing the need to swap grinding pads.

The $\mathrm{M}^{2}$ lab has also made improvements to ultrasound-assisted grinding. By applying ultrasound to a grinding tool, the $\mathrm{M}^{2}$ team was able to decrease grinding forces and therefore temperature, while also improving the quality of the ceramic

is surface engineering, a field which ncompasses a variety of technologies performance of ceramics. $\mathrm{M}^{2}$ has performed research into both modifying and evaluating the surfaces of ceramics.

The $\mathrm{M}^{2}$ lab is now most interested in the various methods used to modify surfaces of ceramics to change and The ise their tribological properties. The methods the team have researched include he $\mathrm{M}^{2}$ Laboratory has a wide-ranging interest in ceramics, especially surface of ceramics, in systems of high speeds, high friction and high temperatures. using a laser to create surface. Retrofitting a grinding head onto which decrease friction; altering the a contactless energy transter head, the surface residual stress of ceramics to team created a tool which is able to drill optimise their friction and wear; and slender holes into very dense ceramics they have proposed a novel evaluation like silicon nitride, as well as having the system for grading the surfaces of capability to produce deep cavities to create a ceramic combustor.

With this comprehensive understanding of the grinding and polishing process, the $\mathrm{M}^{2} \mathrm{lab}$ now has a technique to perform every step of the ceramic facturing process.

SURFACE MODIFICATION AND EVALUATION A final area of research for the $\mathrm{M}^{2} \mathrm{lab}$ ceramic matrix composites.

THE FUTURE IS CERAMIC ranging interest in ceramics, especially their properties in systems which involve high speeds, high friction and high temperatures. This kind of research is invaluable for finding new materials and methods for processing them, to create throw at them.

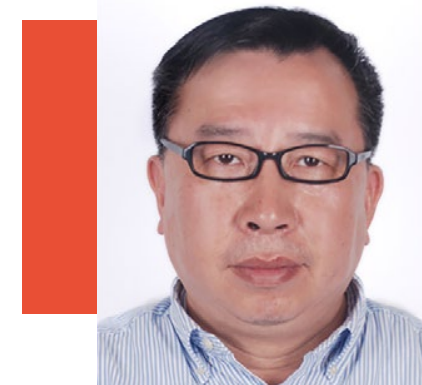

\section{Behind the Research}

\section{Professor Bin Lin}

\section{Research Objectives}

$M^{2}$ refers to the coupling of "Novel Materials" " on the research of both material properties and manufacturing processes, which results in excellent performance of material applications. The team is now working on ceramics processing technology and ceramic material composites (CMCs) facing advanced optical

\section{Detail}

No. 135 of Yaguan Road

Jinnan District
Tianjin, China

M1

\section{MATTERIAL}

in Lin is a professor and doctoral supervisor in Tianjin of advanced ceramics and processing technology. ministry of education. His research interests include high-precision machining of ceramics and composites, manufacturing equipment.

Funding

Nos. 50975199, 513753 Foundation of China,

Personal Response

$M^{2}$ Laboratory has a wide-ranging interest in varied. Is there one technology created by $M^{2}$ which you feel is the most exciting, or is their combined contribution more important?

II Our research directions are steered tightly to the demands of the industry. From the very beginning. our lab focused on grinding the core components of ceramic engines for a national project of China. During that period, we developed the unsteady grinding industrial projects involving ceramics, and mastered more and more technologies of grinding, polishing, evaluating and applying ceramics. We regard the combination of these technologies as more important than the individual technologles themselves because plenty of practical problems from all kinds II

\section{References}

Lin, B et al (2019). Development and theoretical analysis of novel center-inlet computer-controlled polishing process for high-efficiency polishing of optical surfaces. Robotics and
Computer-Integrated Manufacturing. 59, pp. 1-12 Lin, B et al (2019). Excellent Water Lubrication Additives
for Silicon Nitride To Achieve Superlubricity under Extreme for Silicon Nitride To Achieve Superlubricity under
Conditions. Langmuir. 35(46), pp. 14861-14869 Wei, Jet al (2019). Acoustic emission signal of fiber-
reinforced composite grinding: frequency components reinforced composite grinding: frequency components an
damage pattern recognition. The International Journal of damage pattern recognition. The international Journal of Wei, J et al (2019). Measurement and evaluation of fiber bundle surface of long fiber reinforced woven composites.
Surface Topography: Metrology and Properties. 7 (1), pp. 015003

Wei, Jet al (2018). Friction and wear characteristics of carbon fiber reinforced silicon carbide ceramic matrix (Cf) $\mathrm{SiC}$ composite and zirconia $\left(\mathrm{ZrO}_{2}\right)$ ceramic under diy

Yan, $S$ et al (2018). Hydrogen ion induced ultralow wear of
PEEK under extreme load. Applied Physics Letters. $112(10)$ pp. 101601

Liu, P et al (2017). Fluid hydrodynamic fixed abrasive grinding based

Luan, Y J et al (2017). Innovative Contactless Energy Transfer
Accessory for Rotary Ultrasonic Machining and Its Circuit Compensation Based of

. $64(10), p p .7810-7818$

Wang, A et al (2017). Aqueous lubrication and surface milcostructures of engineering polymer materials (PEEK and Li, Y et al (2016). Preliminary study of disc hydrodynamic Wang, Y et al (2016). Feasibility study of the ultrasonic
vibration filing of carbon fiber reinforced silicon carbide composites International Journal of Machine Tools and Manufacture. 101, pp. 10-17

Zhu, $X$ et al (2016). Power Transfer performance and cutting force effects of contactless energy transfer system for
rotary ultrasonic grinding. IEEE Transactions on Industria Electronics. 63(5), pp. 2785-2795 Wei, Jet al (2015). Two-dimensional evaluation of 3D Sufface Science. 355, pp. 166-170

Wang, Y et al (2014). Study on the system matching of materials processing International Journal of Machine Tools and Manufacture. 77, pp. 66-73 